\title{
IdeAs
}

Idées d'Amériques

\section{Gleizer, González Tuñón y Gelman: rosas blindadas}

Gleizer, González Tuñón et Gelman : roses blindées

Gleizer, González Tuñón et Gelman : steel roses

\section{Gema Areta Marigó}

\section{OpenEdition \\ Journals}

Édition électronique

URL : https://journals.openedition.org/ideas/1868

DOI : 10.4000/ideas. 1868

ISSN : 1950-5701

\section{Éditeur}

Institut des Amériques

\section{Référence électronique}

Gema Areta Marigó, « Gleizer, González Tuñón y Gelman: rosas blindadas », IdeAs [En ligne], 9 | 2017, mis en ligne le 05 octobre 2017, consulté le 20 octobre 2022. URL : http://journals.openedition.org/ ideas/1868 ; DOI : https://doi.org/10.4000/ideas.1868

Ce document a été généré automatiquement le 20 octobre 2022.

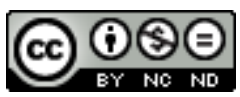

Creative Commons - Attribution - Pas d'Utilisation Commerciale - Pas de Modification 4.0 International - CC BY-NC-ND 4.0

https://creativecommons.org/licenses/by-nc-nd/4.0/ 


\title{
Gleizer, González Tuñón y Gelman: rosas blindadas
}

\author{
Gleizer, González Tuñón et Gelman : roses blindées \\ Gleizer, González Tuñón et Gelman : steel roses
}

Gema Areta Marigó

\section{Los nuevos orígenes de los 50}

1 En 1956, año en el que Ezequiel Martínez Estrada acaba su espectroscopia sobre el peronismo en ¿Qué es esto? Catilinaria, Oliverio Girondo publica su edición definitiva de En la masmédula y Juan Gelman su primer poemario Violín y otras cuestiones, con prólogo de Raúl González Tuñón en la Editorial de Manuel Gleizer iniciando la colección «El Pan Duro». Volvían así a unirse dos poetas esenciales de la vanguardia bonaerense, Girondo y González Tuñón, tutelando de algún modo a la generación del 50, colaboración de destinos y disonancias en las «escrituras agónicas de la modernidad periférica» ${ }^{1}$, representadas igualmente en el panfleto de Martínez Estrada y su revisión del populismo(«el peronismo es una forma soez del "alma del arrabal”»² (Martínez Estrada E., 2005: 52).

2 En la contraportada del libro de Gelman se encontraba la siguiente nota:

El sello MANUEL GLEIZER que hace treinta años diera a conocer a otros entonces jóvenes poetas, hoy convertidos en los valores más maduros de nuestra lírica, ha querido que uno de ellos, RAÚL GONZÁLEZ TUÑóN, lo prologara. La obra de aquellos permanece viva, y se continúa en estos otros, animados por idéntica pasión ciudadana.[...] Desde su alta serenidad juvenil VIOLÍN Y OTRAS CUESTIONES es un anticipo de madurez y compromiso. Un mensaje abierto a los cuatro rumbos de la esperanza. (Gelman J., 1956)

El comienzo de la carrera poética del futuro Premio Cervantes se había gestado en 1955 desde el grupo El Pan Duro formado -como glosan en su antología de 1963- al albur de la militancia de izquierdas («éramos miembros de la Juventud Comunista o estábamos cerca. Eso nos juntó» («Entrevista con Juan Gelman», 2006) con un «pueblo ametrallado 
y flores y marineros en andas en las calles del barrio norte, con multitudes humilladas y la revancha de la minoría celebrada en funciones de gala y recepciones de embajada» según recogen en su antología (El pan duro, 1963: 10). El bombardeo de Plaza de Mayo del 16 de junio de 1955 que había intentado asesinar a Juan Domingo Perón y a sus ministros, una de las peores matanzas de civiles perpetradas por las Fuerzas Armadas en Buenos Aires (que dio lugar a la llamada Revolución Libertadora), se convierte en inmediato contexto político. El cambio será, según Daniel Freidemberg, apartado el peronismo del poder, «factor determinante o al menos gravitante» de una reformulación del campo intelectual con la construcción de un nuevo imaginario poético

[...] basado en la referencia a lo objetivo, lo singular, lo concreto y lo reconocible(que) forma parte de un gesto doble, de reconocimiento y de extrañeza a la vez, que en tanto realista es crítico y que [...] alentado por el pensamiento existencialista [...] tiende a preguntarse por las condiciones de supervivencia en una determinada situación de la cultura y la sociedad. (Freidemberg D., 1999: 186)

4 Los poetas de El Pan Duro entendían «la poesía cada vez más como actitud, la poesía en contradicción con un mundo -y son palabras de uno de nosotros, Juan Gelman- que por su propia esencia niega toda poesía, contribuyendo a anticipar el otro mundo, el mundo de la poesía en libertad» (El pan duro, 1963: 10). Enfrentados a «la inteligencia argentina de mentalidad colonialista» dueña de todos los vehículos de difusión decidirán autopublicarse:

El método era vender bonos de diez pesos, era lo que podía costar un ejemplar. Hacíamos recitales, fiestas populares en clubes como Vélez Sarsfield, íbamos haciendo la edición a medida que teníamos el dinero. Nos reuníamos y elegíamos el orden de publicación en una votación secreta. El primer libro fue el mío, después salió Bandoneón de papel de Héctor Negro, luego El tiempo es un barrio de Julio César Silvain. En el grupo inicial estaban también Hugo Di Taranto, Juan Hierba y Carlos Somigliana. («Entrevista con Juan Gelman», 2006)

5 Parece ser que el encuentro con Gleizer de este nuevo grupo de poetas se produjo a través de Raúl González Tunón, el poeta consagrado que tanto le debía al editor desde su primer poemario El violín del diablo $(1926)^{3}$, título sobre el que parece plegarse el inicio de la carrera poética de Gelman que mantiene un evidente paralelismo con aquel (junto a la coincidencia en el instrumento musical tenemos el prólogo), aunque el oficio de poeta y la cultura argentina han evolucionado ya abriéndose a otras cuestiones.

El primer violín poético, el realista ${ }^{4}$ de González Tuñón salió a la luz porque habiéndole dejado a su hermano Enrique los originales del libro este los envió al concurso Gleizer («que después fue, pero muy amigo nuestro y que además de editor era librero» (Salas H., 1975: 34) para inéditos en 1925 y cuyo jurado formado por Alfonsina Storni, Evar Méndez y Carlos Alberto Leumann ${ }^{5}$ le otorgaría el premio consistente en la edición. Gleizer editaría también sus siguientes poemarios Miércoles de ceniza (1928) y La calle del agujero en la media (1930), y una parte importante de la obra de Enrique González Tuñón: Tangos (1926), El alma de las cosas inanimadas (1927), La rueda del molino mal pintado (1928), El tirano (1932), Camas desde un peso (1932), El cielo está lejos (1933) y Las sombras y la lombriz solitaria (1933). 


\section{Maestro de maestros}

7 Poeta del suburbio, extraño, mágico, trágico y grotesco como su violín, Raúl González Tuñón fue un poeta errante y viajero, un poeta de la calle y de los libros, de las cosas mágicas y vulgares del mundo, cuyo desplazamiento tiene mucho que ver con la ubicuidad de su poesía en Florida ${ }^{6}$ («representante indiscutible del martinferrismo» para Horacio Salas en su prólogo a la edición facsimilar de la revista homónima, Salas H., 1995: XIII), en Boedo (César Fernández Moreno en La realidad y los papeles. Panorama y muestra de la poesía argentina), o en el tránsito entre ambos grupos (el propio Borges dirá que «"Raúl González Tuñón comenzó actuando en "Boedo" y luego pasó a "Florida"» (Borges J. L., 2003: 327).

8 Para Isabel Stratta que lo considera contemporáneo y compañero del grupo de Florida, la poesía de Raúl González Tuñón se construye «al margen de las obsesiones centrales del grupo, de su veneración por la metáfora, de sus inquietudes por la argentinidad y la pureza fonética» (Stratta I., 1989: 185-186), levantando una poesía «hecha de mezcla de registros, de contaminaciones lingüísticas» desde una creciente politización y una imagen de escritor comprometido que permitiría su recuperación veinte o treinta años más tarde (Stratta I., 1989: 186). Añadiríamos quizás que la indiscutible alianza que se establece entre su obra poética y la narrativa grotesca de su hermano Enrique (en pliegues infinitos no suficientemente analizados) permite situar a los hermanos en esa «tercera zona o zona alternativa», en la frontera de Florida y Boedo, en la del arte purismo y el arte comprometido, donde Ana Ojeda Bär y Rocco Carbone sitúan la narrativa de Enrique (Ojeda Bär A. y Carbone R., 2006: 26). Esta marginalidad o mezcla, este tránsito entre ambos grupos es además un rasgo común a muchos otros autores (Roberto Arlt, Nicolás Olivari, Roberto Mariani, Scalabrini Ortiz...), producto de la evolución y riqueza de sus respectivas propuestas, de los necesarios ajustes en la profesionalización de un escritor, apareciendo (como comprobaremos en Raúl González Tuñón) en los recuerdos retrospectivos donde convergen, se integran y aglutinas sus diversos componentes.

El acercamiento de El Pan Duro a Raúl González Tuñón y la posterior invitación a una lectura de poemas en el teatro «La Máscara» (realizada en 1955) terminan con el necesario enlace con el editor Gleizer, quien para entonces se encontraba al final de su trayectoria editorial en un proceso de franca decadencia. Según recuerdos del propio Gelman:

Nos acercamos a Tuñón, éramos perfectos desconocidos, había una riviera grande con él, por ejemplo, en mi caso por el tema de Buenos Aires, yo ya había hecho toda la carrera porteña (la milonga, el billar, el café) y él ya estaba en su apogeo [...]; yo creo que él fue el que mejor pescó de todo ese grupo junto a Homero Manzi, los que mejor expresaron el alma de la ciudad; el hermano de Raúl González Tunón decía que la ciudad es un estado de ánimo; bueno, entonces nosotros nos acercamos a él, era un hombre modesto, nunca quiso ser el Neruda del movimiento poético nacional, claro, para hacerlo necesitaba el apoyo del partido político donde él estaba pero que criticaba en el periódico El Clarín; y una vez lo fuimos a ver para llevarle nuestras cosas, para que las viera, nosotros habíamos creado una suerte de cooperativa que se llamaba El pan duro para publicarnos a nosotros mismos [...]. Una vez hicimos un recital en un teatro del centro e invitamos a Raúl y él vino, le gustaba lo que hacíamos como grupo, y cuando se trataba de sacar el primer libro (el mío) él decidió escribir un prólogo, donde además polemiza con lo cuadrado del Partido Comunista Argentino, y sugirió que Gleizer (uno de los primeros dos 
editores argentinos, antes los libros se editaban en imprentas, no había colecciones, no había nada de eso, en el año 1922 comenzó a publicar a jóvenes desconocidos como Marechal, Borges, Girondo y toda la familia), que era un viejo encantador, que ya no editaba más, prestara el sello por sugerencia de Raúl y ese fue el origen, después se agregaron poetas pero lo fundamos seis en principio. («Entrevista con Juan Gelman», 2006)

10 A la decisión democrática del grupo de publicar primero a Gelman se unió el explícito apoyo de Raúl González Tuñón y la decisión de escribir su presentación ${ }^{7}$, tándem Gelman/Tuñón que terminaría en Gleizer quien a mediados de los cincuenta se convierte, una vez más, en el impulsor de una nueva generación poética. Para entonces, como señala Gelman:

Estaba viejo, ya no editaba pero -muy generosamente- cedió su sello. En la década de 1920 Gleizer había publicado los primeros libros de Borges y de Marechal cuando ellos eran desconocidos. Fue un verdadero editor en una época en que los que publicaban libros eran las imprentas. Gleizer era un inmigrante judío de Ucrania, empezó en Villa Crespo con un bolichito, en la calle Triunvirato, vendía ropa y era un lector insaciable. («Entrevista con Juan Gelman», 2006)

Heroísmo editorial que será recogido por el propio Raúl González Tuñón en el prólogo escrito para la presentación de Gelman:

Hay un hecho que nos llena de emoción y de orgullo: en este país, donde la mayoría de los editores subestiman a la poesía, y, como hemos dicho antes, para que el libro de un poeta sea publicado, el autor tiene que empezar por no ser argentino, y si lo es, sus versos deben ser anodinos, conformistas, inofensivos, «Violín y Otras Cuestiones», de un poeta prácticamente desconocido, aparece con el honroso rubro de Manuel Gleizer, «el último romántico de los editores», como lo llamara mi hermano Enrique, que hizo conocer a toda una generación de poetas, ignorados en su mayoría o algunos de los cuales ya combatidos por la pacata y chata crítica oficial. Cerrada la famosa librería de la vieja calle Triunvirato, liquidada la Editorial de tanto prestigio, el querido Gleizer siguió en la brega, y ahora se ha encargado de este libro de un novel, en el cual yo saludo sin vacilar a un gran poeta. Con «Violín y Otras Cuestiones»-aquí veo todo un símbolo- se inicia la colección «El Pan Duro» y otros jóvenes inéditos serán revelados. Así, el más viejo de los editores publica al más joven de los poetas, cuando las empresas editoras más poderosas se resisten, generalmente, a publicar libros de poetas argentinos consagrados, y con más razón si se trata de jóvenes desconocidos...(González Tuñón R., 1956: 12)

12 Sabemos por ese mismo prólogo que el maestro sentía especial preferencia por los poemas de Gelman porque durante la lectura en el teatro de los inéditos de esa novísima promoción le interesó en particular «El caballo de la calesita», que consideraba magistral. Aunque no existía ningún distribuidor oficial, Violín y otras cuestiones «se agota prontamente, vendido ejemplar por ejemplar, por el autor, sus compañeros de grupo y todos los amigos que se acercan a esta trinchera para poner el hombro. La empresa tiene mucho de heroica por sus circunstancias» (El pan duro, 1963: 12). Este resultado alentador seguramente incitará a que Gleizer publique, como estaba programado, Bandoneón de papel (1957) de Héctor Negro y El tiempo es un barrio (1958) de Julio César Silvain.

13 La carrera poética de Gelman se vinculaba, como era ya una tradición, con aquel «Napoleón de los editores» de quien parecía depender desde hacía tiempo la vida literaria argentina, según recogía el elogio publicado en última Hora el $1^{\circ}$ de Junio de 1926 donde se distinguían dos periodos «antes de Gleizer y después de Gleizer» ${ }^{8}$. En 1918 Gleizer, inmigrante judío proveniente de Rusia, había arribado a Villa Crespo convirtiéndose en uno de sus primeros bohemios al fundar una librería en la calle 
Triunvirato que sería el hogar natural de los nuevos, a quienes conquistaría con su inteligencia y carácter. La legendaria librería La Cultura fue no solo (primero) puente de plata entre editores y literatos sino (después) centro editorial de los futuros y más grandes escritores del país. El editor de los escritores sin libro se estrenó en 1922 con Cómo los vi yo de Joaquín de Vedia, siendo Megatón de Bernardo Verbitsky (1962) su último libro. Llegó a publicar cerca de 300 títulos, entre los que se encontraban Los aguiluchos (1922) de Leopoldo Marechal, La musa de la mala pata (1926) de Nicolás Olivari, los primeros libros de los hermanos González Tuñón, El idioma de los argentinos (1928), Evaristo Carriego (1930) y Discusión (1932) de Borges, No toda es vigilia la de los ojos abiertos (1928) de Macedonio Fernández, y El hombre que está solo y espera (1931) de Scalabrini Ortiz. La figura de Gleizer (junto a las de Samuel Glusberg, Jacobo Samet, Antonio Zamora y Juan Carlos Torrendell) responde a esa emergencia del editor moderno estudiada por Verónica Delgado y Fabio Expósito en el periodo de entreguerras cuando se produce «una nueva distribución de la lectura y la escritura que alcanza a los sectores medios y populares, favoreciendo la emergencia de un nuevo editor cuyas funciones, en tanto agente de un campo intelectual y literario autónomo, se identifican con las del "difusor, animador o del propiciador"» (Delgado V y Expósito F., 2006: 64). $\mathrm{Su}$ carácter diferencial supone un alejamiento de los viejos agentes de la cultura argentina ligados a la edición y a la «propaganda cultural», al tiempo que «la literatura alcanza una dimensión efectivamente más pública y se convierte en un objeto democratizado", tanto en las nuevas colecciones destinadas a los sectores populares como en la producción literaria de consumo más restringido 9 (Delgado $\mathrm{V}$ y Expósito F., 2006: 64-65). El estímulo de seguir publicando (y descubriendo) autores promisorios, en un canon de la literatura que estos representantes de una «época heroica» ayudaban a construir, haría que Gleizer saliera de su retiro, siendo su inductor Raúl González Tuñón quien cobra un protagonismo indiscutible, porque como le comentó a Horacio Salas «me tocó descubrir a Juan Gelman, a Héctor Negro, entonces desconocidos que leían sus versos en un teatro independiente, y luego a Julio César Silvain» (Salas H., 1975: 137).

\section{Confluencias}

El prólogo que Tuñón le hace a Gelman es como remarca Daniel Freidemberg «un acto de transmisión» que no puede pasar inadvertido, reponiendo un repertorio de inquietudes y preferencias ya realizado en los años 1920 o en los 1930, actualizándolo y disputando la primacía (Freidemberg D., 1999: 194).También es un acto de legitimación especular iniciado en aquel momento del texto en el que le da la bienvenida: «Juan Gelman irrumpe dignamente en la poesía de habla española y el círculo universal de la rosa» para inmediatamente escribir que «En su libro palpita un lirismo rico y vivaz y un contenido principalmente social, pero social bien entendido, que no elude el lujo de la fantasía» (González Tuñón R., 1956: 10). De esta forma Tuñón defiende tanto la poesía de Gelman como la suya propia a través de una convergencia que extenderá a todo un balance de «nuestra tradición» a través del tiempo ${ }^{10}$. El gesto interpuesto (necesario como hilo conductor, tú/yo) desaparecerá, no así el contenido, que permanece inalterable: cuando Gelman afirme sus propias evidencias expresivas en 1973, explicará que en su primer libro estaban ya presentes «las dos ondas de mi poesía posterior, 
hasta hoy, lo lírico y lo social, lo real y lo imaginado. Juancito Caminador y el poeta comprometido» (González Tuñón R., 1973: 9).

El poeta que escribe la introducción a Gelman en los cincuenta ha recorrido múltiples caminos («A fuerza de sufrir por esos caminos me hice optimista» (Vignale P. J. y Tiempo C., 1977) contemplando el mundo de cerca con sus paraísos e infiernos terrenales: la bohemia literaria (siguiendo las huellas de sus admirados Baudelaire y Carriego), las calles de múltiples ciudades (fundamentales Buenos Aires, París, Madrid y Santiago de Chile), los circos ambulantes, los puertos del mundo con sus tabernas costeras y prostíbulos, las trincheras con sus hospitales de sangre (en la Guerra del Chaco, en la Guerra Civil Española)... En fin, la dureza y la belleza de la vida desde una poesía entendida como «ese equilibrio entre el recuerdo y la predicación/entre la realidad y la fábula/debe fijar los grandes hechos memorables» (González Tuñón R., 1963: 29).

$16 \mathrm{Su}$ «amor por los puertos y el vagabundaje y los viajes» viene de sus dos abuelos: el imaginero Estanislao González (modelo de su alter ego Juancito Caminador ${ }^{11}$ ) cuyas historias le contaba su padre, y el obrero metalúrgico Manuel Tunón que lo lleva todos domingos a la dársena a comer pescaditos fritos y con nueve años a una manifestación (modelo del poeta social) (Salas H., 1973: 16-17). Entre sus viajes iniciáticos su primera ida a Europa, y en especial a París, con el dinero obtenido del Premio Municipal de poesía por su segundo libro Miércoles de ceniza (1928), en un viaje que duró de 1929 a 1930. El poemario La calle del agujero en la media (1930), producto del deslumbramiento vital europeo, supone uno de los primeros virajes de su poesía, finalizando el ciclo Gleizer con un libro donde para Mónica Bueno «está la clave de su decisión de convertirse en un poeta revolucionario» cuando surrealismo y revolución formen una ecuación cuya tensión productiva no abandonará hasta el final de su escritura (Bueno M., 2017).

17 Pero este poeta caminador (cuyo primer poema dedicado a Frank Brown apareció en Caras y Caretas) se forma en el ejercicio del periodismo, savia nutricia que estimula el embrión del poema, cuyo balance para Germán Ferrari ${ }^{12}$ constituye una producción inabarcable y desperdigada en medios masivos y medios alternativos o de tirada reducida, en una carrera que atravesó casi cincuenta años de la vida nacional e internacional. A sus primeras incursiones en las revistas literarias Proa y Martín Fierro le siguen los diarios como Crítica, La Nación, El Hogar, Mundo Argentino...y Clarín desde 1948 hasta su jubilación en 1969. Será su faceta de corresponsal del diario Crítica de Natalio Botana el que lo llevará a Tucumán (1927), a Brasil (1931), al Chaco (1932), a la Patagonia (1933). Viajará a España primero en 1935, volviendo en 1937 como corresponsal del periódico republicano de Buenos Aires La Nueva España para cubrir la Guerra Civil.

Para 1956 su producción, contando los tres libros editados por Gleizer, estaba compuesta por diez poemarios: Todos bailan. Los poemas de Juancito Caminador (Buenos Aires, Azul, Don Quijote, 1934), La rosa blindada. Homenaje a la insurrección de Asturias y otros poemas revolucionarios (Buenos Aires, Federación Gráfica Bonaerense, 1936), La muerte en Madrid (Buenos Aires, Ediciones Feria, 1939), Canciones del Tercer Frente (Buenos Aires, Problemas, 1941), Himno de pólvora (Santiago de Chile, Editorial Nueva América, 1943), Primer canto argentino (Buenos Aires, Edición del Autor, 1945), y Hay alguien que está esperando (el penúltimo viaje de Juancito Caminador) publicado por Carabelas en $1952^{13}$. 
19 Es este poeta quien incide en el hibridismo de Gelman con un texto introductorio que debe leerse desde el interior de ese debate literario de estéticas representativas del "posperonismo»" ${ }^{14}$, donde como apunta Miguel Dalmaroni la discusión entre el realismo de Lukács y el modernismo vanguardista de Brecht (que se desarrolla en Europa durante la década de 1930) «encontrará un campo propicio en la larga serie de disidencias y desprendimientos del partido comunista a fines de los años cincuenta» (Dalmaroni M., 2004: 19).

María Fernanda Alle recuerda que el posicionamiento de Raúl González Tuñón, respecto al partido (al que se había afiliado en 1934) era por esos años ambiguo y difuso «sin desvincularse de su estructura, pero discutiendo muchos de sus dogmas; cerca de los jóvenes de la nueva izquierda, pero increpado por la dirigencia a causa de ese vínculo» (Alle M. F.). La polémica con «lo cuadrado del Partido Comunista» (en palabras de Gelman) tiene como antecedente aquella situación de los escritores de izquierda en los treinta estudiada por Sylvia Saítta, «entre la cultura y la política», donde no dejaron de sucederse «encontronazos y malentendidos de los intelectuales considerados de izquierda con el Partido Comunista, en un debate que puso en el centro las tensiones existentes entre militancia comunista y actividad intelectual» (Saítta S., 2001: 406). Las diferentes etapas que podemos distinguir en la poesía de Raúl González Tuñón se encuentran fuertemente articuladas con una serie de movimientos específicos del intelectual comunista, así podemos reconocer un primero periodo hasta mediados de 1930, con la publicación de su poema «Las brigadas de choque» en el cuarto número de su revista Contra. La revista de los franco-tiradores (editada entre abril y septiembre de 1933) por el que pasó algunos días preso procesado por incitar a la rebelión, logrando la libertad bajo «caución juratoria».

21 Aunque la revista Contra fue para Saítta «el primer programa estético-político colectivo que vinculó vanguardia estética con vanguardia política en la Argentina» (Saítta S., 2005: 13) es cierto según anota Hernán Camarero que a pesar de «intentar mantener su autonomía del PC y un carácter más pluralista» su director formuló definiciones contundentes del tipo «[...] el único camino posible es el del comunismo. Hay proletarios y burgueses, y yo estoy con los proletarios, si no por mi cultura y mi condición de periodista, por, entiéndase mi mentalidad revolucionaria»" ${ }^{15}$ (Camarero H.). En el poema «Las brigadas de choque» Tuñón adoptará un «nosotros, los comunistas» para arrojar su violento poema quebrado contra el rostro de la burguesía. Estas brigadas de choque de la Poesía no pudieron formar parte de su libro Todos bailan mientras se sustanciaba la causa, y el poema quedó olvidado hasta su reedición por la revista La Rosa Blindada en 1965 donde su autor manifiesta haberlo escrito

[...] en uno de los peores momentos de la historia argentina y los clerical-fascistas que dominaban entonces [...] los agresivos versos, su iracundia, no gratuita, como la de algunos jóvenes en la actualidad, que no precisan el destinatario de su inconformismo, y algo de profético, los convierten en un documento más o menos curioso. Son visibles sus defectos formales y de fondo, exageraciones, injusticias. Debe disculparse lo que tiene de sarampión revolucionario, de extremismo, esa enfermedad infantil del comunismo señalada por Lenin. ${ }^{16}$

Entre mediados de los veinte a mediados de los treinta Raúl González Tunón lleva a cabo, según Beatriz Sarlo, una serie de «operaciones de carácter ideológico y estético que difieren de las de la vanguardia martinferrista» ${ }^{17}$ (Sarlo B., 1988: 155), lo hace desde su lugar de "periodista estrella» como condicionante de una escritura igualmente dependiente de la progresiva «legitimación de posiciones de izquierda en el campo 
intelectual argentino» a pesar de las persecuciones y actos de censura posteriores a 1930 (Sarlo B., 1988: 157). Sus primeros libros son así «un verdadero laboratorio de transformaciones ideológico-literarias donde se verifica el impacto productivo de los grandes temas sociales sobre los mundos referenciales de la literatura» (Sarlo B., 1988: 158), y donde se inicia un itinerario que para Sarlo va desde «el margen cosmopolita al internacionalismo» (Sarlo B., 1988: 158), donde se producirá «el pasaje del poeta marginal al poeta político» (Sarlo B., 1988: 173).

El corte que para Tuñón supone La rosa blindada, «ruptura dramática, y a ese libro siguieron grandes tragedias, muchas muertes y exilios» (Salas H., 1975: 130), tuvo como prolegómeno Todos bailan. Los poemas de Juancito Caminador (1935) donde el alter ego, creado en Miércoles de ceniza (1928) desde el poema en prosa «Cosas que le ocurrieron a Juancito Caminador», da paso según Susana Cella no tanto al cierre de una etapa como a «la coexistencia de tendencias y rasgos que estuvieron y seguirá presentes en su poesía» (Cella S., 2000: 65), una recapitulación mostrada en el primer poema «Historia de veinte años», y cuyo manifiesto se encuentra en el poema "Juancito Caminador» cuyos dos primeros versos dicen: «Traigo la palabra y el sueño, la realidad y el juego del inconsciente/lo cual quiere decir que yo trabajo con toda la realidad».

El impacto ideológico-político de la revolución, el encuentro con la Rusia de los soviets y con el Octubre Rojo de Asturias en 1934 fueron experiencias principales de una serie de escritores de izquierda que, como afirma Sylvia Saítta (Saítta S., 2001: 387), encontraron en estos modelos la utopía revolucionaria. En el prólogo «A nosotros la poesía» con el que se inicia La rosa blindada. Homenaje a la insurrección de Asturias y otros poemas revolucionarios (1936) Raúl González Tuñón cree haber resuelto los problemas fundamentales que «la cuestión arte-política me ha planteado»:

Y si una pretensión tengo es la de ser un poeta revolucionario, la de haber abandonado esa especie de virtuosismo burgués decadente, no para caer en la vulgar crónica chabacana que pretende ser clara y directa y resulta ñoña, sino para vincular mi sensibilidad y mi conocimiento de la técnica del oficio a los hechos sociales que sacuden al mundo. Sin que lo político menoscabe a lo artístico o viceversa, confundiendo, más bien, ambas realidadesen una. (González Tuñón R., 1963: 12)

Su obra testimonial sobre España comenzada con la insurrección minera de Asturias y su masacre -que se extiende a 8 documentos de hoy (1936), Las puertas del fuego (1938), y La muerte en Madrid (1939)-vincula su producción con esa «poesía de guerra», un tipo particular de escritura poética que para Susana Cella remite a la poesía social y a la función ideológica de la poesía, lo que produce una ampliación del lenguaje poético en «factores como la comunicatividad, exhortación, denuncia, en fin, forma de la ideología que ha de manifestarse de modos diversos pero no ambiguos: a favor o en contra» (Cella S., 2000: 67-68). En España como militante marxista González Tuñón ha encontrado para sí, especifica Alberto Julián Pérez, un nuevo papel: el de intelectual, formando "parte de este grupo de artistas y humanistas (políticos, historiadores, politólogos, filósofos, etc.) que se denominan "intelectuales" y consideran que sus opiniones deben guiar a la sociedad civil» (Pérez A. J.).

Será esta poética de la convocatoria, que estructura su Primer canto argentino (1945) según detallado análisis de María Fernanda Alle (Alle M. F., 2014: 82), la que articula su presentación de Gelman que se abre con la cita de Shelley «Los poetas son los legisladores no reconocidos del mundo», y termina con otra de John Keats «Jamás la poesía de la tierra se extingue», comentando «y dijo una gran verdad. A cada 
generación, en cualquier lugar del mundo, surge un nuevo poeta para probarlo». Tuñón adelanta así parte del programa aparecido en su libro póstumo de crónicas y ensayos La literatura resplandeciente (1976) sobre la necesidad de ir «Hacia el realismo romántico»: «Debemos buscar el punto en donde se encuentran lo clásico y lo romántico, la experiencia y el sentimiento, la ley y la revelación, la búsqueda y la inspiración. El realismo romántico. Seamos realistas románticos» (González Tuñón R., 1976: 151).

Violín y otras cuestiones se abre con unos versos que parecen seguir estos mandatos: "¡Quién pudiera agarrarte por la cola/magiafantasmanieblapoesía!/¡Acostarse contigo una vez sola/y después enterrar esta manía!/¡Quién pudiera agarrarte por la cola». Se cumple de esta forma (con estas formas) la recepción de un legado dependiente tanto de aquellos editores que revolucionaron la cultura argentina durante las vanguardias como de los nuevos continuadores de la batalla por la poesía en rebelión recogiendo (y así lo manifiestan los poetas de El Pan Duro) «la rosa que blindara Raúl González Tuñón» (El pan duro, 1973: 10).

\section{BIBLIOGRAPHIE}

Abós, Álvaro, El posperonismo, Buenos Aires, Legasa, 1986.

Alle, María Fernanda, «Poesía para “cambiar el mundo”: Raúl González Tuñón y la definición de una poética de la convocatoria», http://www.celarg.org/int/arch_publi/ alle_mar_a_fernandacc.pdf [Página consultada el 15 de febrero de 2017].

Alle, María Fernanda, «Primer canto argentino de Raúl González Tuñón en 1943 y en 1945: la eficacia de la poesía», OrbisTertius, vol. XIX, nº 20, 2014, p. 76-84.

Antelo, Raúl, «Estudio filológico preliminar», en Oliverio Girondo, Obra completa, Madrid/Paris, Colección Archivos, ALLCA XX, 1999,p. XXVII-LXXXIX.

Borges, Jorge Luis, «”Florida” y “Boedo”. Un movimiento enjuiciado por sus actores y por los artistas de hoy", Textos recobrados (1956-1986), Buenos Aires, Emecé, 2003, p. 327-329.

Bueno, Mónica, «Raúl González Tuñón: un poeta revolucionario (Una biografía:ética y escritura)», http://www.razonyrevolucion.org/jorn/PONENCIAS\%20EN\%20PDF/Mesa\%2016/

Mesa16_Bueno.pdf [Página consultada el 15 de febrero de 2017].

Cella, Susana, «Sobre una montaña de ceniza lejana y popular: Raúl González Tuñón», Inti, no 52-53, Otoño-Primavera 2000, p. 57-78.

Contra. La revista de los franco-tiradores, Buenos Aires, Editorial de la Universidad Nacional de Quilmes, 2005.

Dalmaroni, Miguel, La palabra justa: Literatura, crítica y memoria en la Argentina, 1960-2002, Buenos Aires, Santiago de Chile/Melusina, RIL, 2004, http://www.memoria.fahce.unlp.edu.ar/library? $\mathrm{a}=\mathrm{d} \& \mathrm{c}=$ libros\&d=Jpm1 [Página consultada en 15 de febrero de 2017]. 
Delgado, Verónica y Fabio Expósito, «La emergencia del editor moderno», en José Luis de Diego (dir.), Editores y políticas editoriales en Argentina, México, Fondo de Cultura Económica, 2006, p. 59-89.

El pan duro. Grupo de Poesía, Buenos Aires, Ediciones La Rosa Blindada, 1963.

«Entrevista a Juan Gelman», Clarín, 11-03-2006, http://edant.clarin.com/suplementos/cultura/ 2006/03/11/u-01156299.htm [Página consultada el 15 de febrero de 2017].

«Entrevista con Juan Gelman»,http://www.letras.s5.com/it090211.html[Página consultada el 15 de febrero de 2017].

Fernández Moreno, César, La realidad y los papeles. Panorama y muestra de la poesía argentina, Madrid, Aguilar, 1967.

Ferrari, Germán, Raúl González Tuñón periodista, Buenos Aires,Ediciones del Centro Cultural de la Cooperación, 2006.

Freidemberg, Daniel, «Herencias y cortes. Poéticas de Lamborghini y Gelman», en Susana Cella (dir.), La irrupción de la crítica, Buenos Aires, Emecé, 1999, p. 183-212.

García Costa, Víctor O., «El último romántico de los editores», en Víctor O. García Costa y María de los Ángeles Marechal, Manuel Gleizer librero y editor, Buenos Aires, Peña del Libro «Trenti Rocamora», 2008, p. 3-11.

Gasió, Guillermo, Que sean libros en blanco, Estudio preliminar de Gabriela García Cedro, Buenos Aires, Teseo, 2011.

Gelman, Juan, Violín y otras cuestiones, Buenos Aires, Gleizer, 1956.

González Tuñón, Raúl, «Prólogo», en Juan Gelman, Violín y otras cuestiones, Buenos Aires, Gleizer, 1956, p. 9-13.

González Tuñón, Raúl, La rosa blindada, Buenos Aires, La Rosa Blindada, 1963.

González Tuñón, Raúl, «Presentación», El violín del diablo. Miércoles de ceniza, Buenos Aires, La Rosa Blindada, 1973, p. 7-10.

González Tuñón, Raúl, La literatura resplandeciente, Buenos Aires, Editorial Boedo, 1976.

Kohan, Néstor, La Rosa Blindada. Una pasión de los '60,Buenos Aires, La Rosa Blindada, 1999.

Martínez Estrada, Ezequiel, ¿Qué es esto? Catilinaria, Buenos Aires, Colihue Biblioteca Nacional, 2005.

Ojeda Bär, Ana y Rocco Carbone, «Estudio preliminar», en Enrique González Tuñón, Narrativa 1920-1930, Buenos Aires, El 8vo loco Ediciones, 2006, p. 9-30.

Orgambide, Pedro (comp.), Recordando a Tuñón, Buenos Aires, Instituto Movilizador de Fondos Cooperativos, 1997.

Pérez, Alberto Julián, «Raúl González Tuñón y la Guerra Civil española», http://

www.academia.edu/4233674/

_Ra\%C3\%BAl_Gonz\%C3\%A1lez_Tu\%C3\%B1\%C3\%B3n_y_la_Guerra_Civil_espa\%C3\%B1ola_[Página consultada el 15 de febrero de 2017].

Prieto, Martín, «Realismo, verismo, sinceridad. Los poetas», en María Teresa Gamuglio (Dir.), El imperio realista, Buenos Aires, Emecé, 2003, p. 321-344. 
Saítta, Sylvia, «Entre la cultura y la política: los escritores de izquierda", en Alejandro Cattaruzza (dir.), Crisis económica, avance del Estado e incertidumbre política (1930-1943), Buenos Aires, Sudamericana, 2001, p. 383-428.

Saítta, Sylvia, «Polémicas ideológicas, debates literarios en Contra. La revista de los francotiradores», en Sylvia Saítta (coord.),Contra. La revista de los franco-tiradores, Bernal, Universidad Nacional de Quilmes, 2005, p. 13-33.

Salas, Horacio, Conversaciones con Raúl González Tuñón, Buenos Aires, La Bastilla, 1975.

Salas, Horacio, «Estudio preliminar», en Martín Fierro 1924-1927. Edición facsimilar, Buenos Aires, Ministerio de Cultura y Educación de la Nación, 1995, p. VII-XV.

Sarlo, Beatriz, «Raúl González Tuñón: el margen y la política», Una modernidad periférica: Buenos Aires 1920 y 1930, Buenos Aires, Ediciones Nueva Visión, 1988, p. 155-178.

Stratta, Isabel, «Girondo y González Tuñón: el vértigo de los viajes y la revolución», en Graciela Montaldo (dir.), Irigoyen entre Borges y Arlt, Buenos Aires, Contrapunto, 1989, p. 185-193.

Vignale, Pedro Juan y César Tiempo, Exposición de la actual poesía argentina, Buenos Aires, Tres Tiempos, 1977.

\section{NOTES}

1. Así nombra Raúl Antelo el dilema o la disyuntiva de la escritura de Oliverio Girondo que extendemos a la de Raúl González Tuñón. Raúl Antelo «Estudio filológico preliminar», en Oliverio Girondo, Obra completa, Madrid/Paris, Colección Archivos, ALLCA XX, 1999,p. XXVIII.

2. Aunque Raúl González Tuñón alguna vez lo llamó «ensayista de tono mesiánico» sus opiniones sobre el general son muy parecidas: «[...] estoy contra Perón pero no contra la masa peronista. [...]. Es un movimiento discutible en sus raíces, pero el error consiste en aplicarle el denominador común de nazi peronistas, cuando el nazi era Perón» (Salas H, 1975,125). El primer elemento apuntado por Martínez Estrada que integra el proceso peronista es precisamente «a) la infiltración de la ideología y la táctica del dominio nazi» (Martínez Estrada, E., 2005: 49).

3. Sabemos que estos «apresurados versos» fueron escritos en Santa Fe y Montevideo (por la nota de presentación de sus poemas en Pedro Juan Vignale P. J. y Tiempo C., 1977: 163). El fondo de este libro, según le confiesa a Horacio Salas, está ligado a su condición de escritor «repentista, en la medida en que soy absolutamente auténtico», y a su forma de ver la vida dependiente de la frase de Roger Bacon «Contempla el mundo» (Salas H., 1975: 33-34).

4. «Puedo decir que en el fondo esa poesía es realista: se nutría, en general, en ambientes, hechos y tipos que existieron. Existió Werner Land, el ex soldado alemán "espartaquista" que había traído un violín absurdo, casi monstruoso que él llamaba del diablo (hoy podría pasar por un objeto "pop" o una "estructura elemental..."). Más de una vez hablé con él en una especie de Café-Concert proletario del Puerto de Santa Fe, donde actuaba, y ahora pienso que era una suerte de precursor de la música beat, ruidosa...» (González Tuñón R, 1973: 8).

5. Martín Prieto comenta que Carlos Alberto Leumann no lo votó (Prieto M., 2003: 324).

6. En Conversaciones con Raúl González Tuñón se declara tipo de Florida (como Roberto Arlt), (Salas H., 1975: 37).

7. Para Raúl González Tuñón escribir un prólogo a un poeta novel era pagar parte de la deuda contraída con todos aquellos autores que le había estimulado (Salas H., 1973: 131).

8. La reseña completa se encuentra recogida en Gasió G., 2011: 188-190.

9. Víctor O. García Costa anota:«No ignoramos las ediciones de La Cultura Argentina, dirigida por José Ingenieros y mecenada por Severo Vaccaro, nacida en 1915, y tampoco la Cooperativa 
Editorial Buenos Aires, fundada por Manuel Gálvez en 1917, pero lo de Manuel Gleizer fue otra cosa, por el esfuerzo personal y por la edición y difusión de autores argentinos, hasta entonces desconocidos, a precios asequibles desde $m \$ n$ 0,50 hasta $m \$ n$ 3,50. Muy excepcionalmente sus ediciones superaban esos precios» (García Costa V. O., 2008: 6).

10. Dice Raúl González Tuñón: «En nuestra tradición, en todo caso, se mezclan, a través del tiempo, románticos como los de Mayo y los de la generación de Echeverría, en la huella del innovador Hugo, en su acento civil; el "gauchismo" genial de los cultos Ascasubi, Hernández, Del Campo; los suntuosos versificadores lugonianos con el maestro cordobés a la cabeza; el urbanismo del Carriego legítimo de "La Canción del Barrio"; el porteñismo y el internacionalismo de muchos de los poetas del movimiento "martinfierrista" y el grupo de "Boedo", casi todos, hijos de españoles e italianos; la poesía popular, la payada, de Gabino Ezeiza, de Betinotti; la poesía lunfarda de Carlos de la Púa y la del tanguero Celedonio Flores; el decoroso tono menor de poetas del Litoral, como José Pedroni (en su origen, lugoniano), hoy lanzado a más altas resonancias civiles, y el de Juan L. Ortiz, tenue, delicado, muchos de cuyos versos aparecen atravesados por ráfagas rilkeanas; el aire pueril de copla de algunos poetas norteños, cultores de un muy discutible, poco auténtico folklore; la poesía cálida y valiente de algunos poetas que devinieron revolucionarios, los auténticos, aquellos en quienes Calíope no ha ahogado a Erato, etc...» (González Tuñón R., 1956: 11).

11. «[...] en Ingeniero White, en Bahía Blanca, conocí a un prestigioso prestidigitador: Juancito Caminador, que se llamaba Johnny Walker. De ahí viene lo de Juancito Caminador. Fue en 1926», Orgambide P., 1997: 34.

12. Consultar Ferrari G., 2006.

13. No incluimos: El otro lado de la estrella (Buenos Aires, Sociedad Amigos del Libro Rioplatense, 1934), poemas, relatos, diálogos, Dan tres vueltas y luego se van (Buenos Aires, Tor, 1934) en colaboración con Nicolás Olivari, 8 documentos de hoy (Buenos Aires, Federación Gráfica Bonaerense, 1936) ensayos, Las puertas del fuego (documentos de la guerra en España), crónicas poéticas (Santiago de Chile, Ercilla, 1938), y Todos los hombres del mundo son hermanos (Buenos Aires, Editorial Poemas, 1954) impresiones de viajes con pocos poemas.

14. Para Miguel Dalmaroni, «el contexto que se ha denominado "posperonista", que en adelante teñirá en mayor o menos medida todas las prácticas del campo cultural» supone la revisión del peronismo (la versión argentina de lo que en política se denomina "populismo") durante el último lustro de los cincuenta en el espacio de la cultura de izquierda (Dalmaroni M., 2004: 20). Según Álvaro Abós, el posperonismo "es el espacio histórico que se abre con el fin de la hegemonía peronista en el campo popular" (Abós A., 1986: 77).

15. La cita de Tuñón pertenece a «Algunas opiniones que explican algunas actitudes», Contra, 2, mayo de 1933, p. 6.

16. El poema se volvió a publicar en el número 4 (1965) en la revista La Rosa Blindada y se encuentra en la selección realizada por Néstor Kohan. (Kohan N., 1999: 103-104).

17. Esas operaciones son: «Lee algunos surrealistas, a los que mezcla desprejuiciadamente con restos de Baudelaire y Whitman en cruces culturales que no estaban en Borges o Girondo; trabaja sobre tópicos que, hasta entonces, habían sido monopolizados por la "literatura social", conservadora desde el punto de vista estético; incorpora productivamente la dimensión política a su poesía y construye, en ella, un nuevo tipo de escritor, viajero y testigo: no sólo el que mira e inventa, sino el que juzga 
y agita; Tuñón altera las formas del viaje literario y rearma el carnet de voyage en sus primeros libros de poemas» (Sarlo B., 1988: 155).

\section{RÉSUMÉS}

Cet article se propose d'étudier l'édition du premier recueil de Juan Gelman Violín y otras cuestiones, édité par Manuel Gleizer en 1956, avec un prologue de Raúl González Tuñón. Nous soulignons que l'accueil que Tuñón fit à Gelman dans "le cercle universel de la rose" passe par la compréhension des ajustements réalisés dans sa propre poétique depuis les années 30 . Il s'agit d'une reformulation qui connaît diverses étapes où le militantisme communiste et le contexte post-péroniste des années 50 sont particulièrement importants.

El artículo estudia la edición del primer poemario de Juan Gelman Violín y otras cuestiones, editado por Manuel Gleizer en 1956, con prólogo de Raúl González Tuñón. Entendemos que la bienvenida de Tuñón a Gelman al «círculo universal de la rosa» pasa por la comprensión de los ajustes realizados en su poética desde los treinta, una reformulación que abarca distintas etapas, donde son especialmente relevantes su militancia comunista y el contexto posperonista de los años cincuenta.

This article studies the publication of Juan Gelman's first collection of poems, Violin y otras cuestiones, published by Manuel Gleizer in 1956 with an introduction by Raúl González Tuñón. It underscores how the reception given by Tunón to Gelman into the " universal poetic circle of the rose " can only be understood through an examination of his own poetic evolution since the 1930s. It is a revision that goes through various stages in which the communist militancy and the post-Peronist context of the 1950s play a major part.

\section{INDEX}

Mots-clés : Manuel Gleizer, Raúl González Tuñón, Juan Gelman, poésie, édition

Palabras claves : Manuel Gleizer, Raúl González Tuñón, Juan Gelman, poesía, edición

Keywords : Manuel Gleizer, Raúl González Tuñón, Juan Gelman, poetry, edition

\section{AUTEUR}

\section{GEMA ARETA MARIGÓ}

Gema Areta Marigó (Séville, 1961) est Professeure de littérature hispano-américaine de l'Universidad de Sevilla, invitée dans de nombreuses universités européennes et latinoaméricaines (France, Mexique, Saint Domingue, Brésil, Cuba). Son doctorat, soutenu en 1990, portait sur La poética de José María Eguren (Alfar, 1993), maître indiscutable de la poésie péruvienne contemporaine, et il donna lieu à la publication de De Simbólicas a Rondinelas (Visor, 1992). Ses recherches sur la poésie péruvienne incluent diverses études sur José María Eguren, mais aussi un hommage à César Vallejo et une attention particulière à Carlos Oquendo de Amat. 
Ses travaux portent également sur les éditions facsimilés (avec prologue critique) des revues éditées par le Cubain José Lezama Lima : Verbum (Sevilla, Renacimiento, 2001), Espuela de Plata (Renacimiento, 2002) y Nadie Parecía. Cuaderno de lo Bello con Dios (Renacimiento, 2006). Ainsi que la revue Orígenes núms. 35-36 de José Rodríguez Feo (Sevilla, Renacimiento, 2008), revue dissidente par rapport à Orígenes que Lezama et Feo publièrent jusqu'en 1954. monluztrella@us.es 